\title{
Cesarean scar ectopic with ruptured corpus luteal cyst: a rare case report
}

\author{
Shikha Yadav*, Shubhra Mukherjee
}

Department of Obstetrics and Gynecology, ESIC Hospital, Nanda Nagar, Indore, Madhya Pradesh, India

Received: 03 February 2019

Revised: 21 December 2019

Accepted: 27 December 2019

\author{
*Correspondence: \\ Dr. Shikha Yadav, \\ E-mail: shikhay26@gmail.com
}

Copyright: () the author(s), publisher and licensee Medip Academy. This is an open-access article distributed under the terms of the Creative Commons Attribution Non-Commercial License, which permits unrestricted non-commercial use, distribution, and reproduction in any medium, provided the original work is properly cited.

\begin{abstract}
Incidence of caesarean scar pregnancy (CSP) is increasing because of a rising number of caesarean sections. Prompt diagnosis of the condition is required to reduce associated morbidity. A high index of suspicion is required for women with a suggestive history of CSP. Ultrasound scan is the diagnostic tool of choice. Management options include medical, surgical and interventional radiology. Appropriate patient selection is important for optimal results. Major haemorrhage and hysterectomy are the main risks associated with CSP. Therefore, adequate counselling and availability of surgical expertise and blood transfusion should be part of a comprehensive management strategy. We are reporting a rare case of G3P2L1 with previous two lower caesarean deliveries diagnosed with caesarean scar ectopic based on clinical and ultrasound finding came with acute pain in abdomen with haemodynamically unstable with intraoperative finding s/o unruptured c scar pregnancy along with ruptured corpus luteal cyst leading to severe intra-abdominal bleeding. C-scar ectopic and corpus luteal cyst confirmed on histopathology.
\end{abstract}

Keywords: Caesarean section, Ectopic pregnancy, Hysterectomy, Laparotomy, Ruptured corpus luteal cyst, Scar ectopic, Ultrasound diagnosis

\section{INTRODUCTION}

Caesarean scar ectopic is one of the rarest of all ectopic pregnancies. It is defined as when a blastocyst implants on a previous caesarean scar. The incidence of caesarean scar ectopic has increased due to increase in number of caesarean deliveries. Early diagnosis of this can be done by using sonography. It is very important because a delay can lead to increased maternal morbidity and mortality. Ultrasound scan is the diagnostic tool of choice. Management options include medical, surgical and interventional radiology. Appropriate patient selection is important for optimal results. Major haemorrhage and hysterectomy are the main risks associated with CSP. Therefore, adequate counselling and availability of surgical expertise and blood transfusion should be part of a comprehensive management strategy.

Caesarean scar pregnancy (CSP) is a rare form of ectopic pregnancy whereby the gestational sac is fully or partially implanted within the scar caused by a previous caesarean section (CS). The first case was reported in 1978., Estimates of CSP incidence range from $1 / 1800$ to $1 / 2500$ of all pregnancies. It has been estimated that $6.1 \%$ of pregnancies in women with at least one previous CS and a diagnosis of ectopic pregnancy will be CSP. ${ }^{3}$ To date, more than 1000 cases have been reported. ${ }^{4,5}$ This is attributable partly to the increasing number of CS performed and also to increasing awareness and better ultrasound diagnosis. 


\section{CASE REPORT}

A 28 years old female and gravida 3 para 2 living 1 with previous history of two lower segment caesarian section was admitted to employee state insurance corporation hospital Indore, Madhya Pradesh with h/o 9 weeks pregnancy with complaints of mild bleeding per vagina off and on since 10 days and acute pain in abdomen lasting for four hours.

On physical examination she presented with pallor, tachycardia (pulse rate 115 beats per minute), tachypnea (respiratory rate 22 breaths per minute), and hyperpyrexia $\left(38.1^{\circ} \mathrm{C}\right)$ with abdominal distention and generalized abdominal tenderness with severe rigidity on the lower quadrants on palpation. Blood pressure (BP) was $85 / 60 \mathrm{mmHg}$ and she was anxious but alert and conscious. Speculum examination revealed bleeding through cervical OS. In bimanual examination the uterus seemed to be enlarged up to 6 to 8 weeks of gestation however exact size could not be made out due to abdominal distension due to fluid and severe tenderness on bimanual examination.

USG finding shows empty uterine cavity and empty cervical canal with a gestational sac in anterior myometrium of lower uterine segment. The gestational sac had a fetal pole, showing fetal cardiac activity. and having average gestational age of 8 weeks 1 day. Anterior myometrium anterior to the gestational sac was thinned out and 4 x $5 \mathrm{~cm}$ heterogenous complex ovarian mass s/o ?? haemorrhagic cyst ?? ovarian ectopic pregnancy and haemorrhagic fluid in paracolic gutter and cul-de-sac.

Lab reports shows $\mathrm{Hb} 7.5 \mathrm{gm} / \mathrm{dl}$ and Hct - 26\%, platelet count $2.34 \times 1000$ per $\mathrm{ml}$, coagulation profile with in normal limit and normal renal and liver function tests.

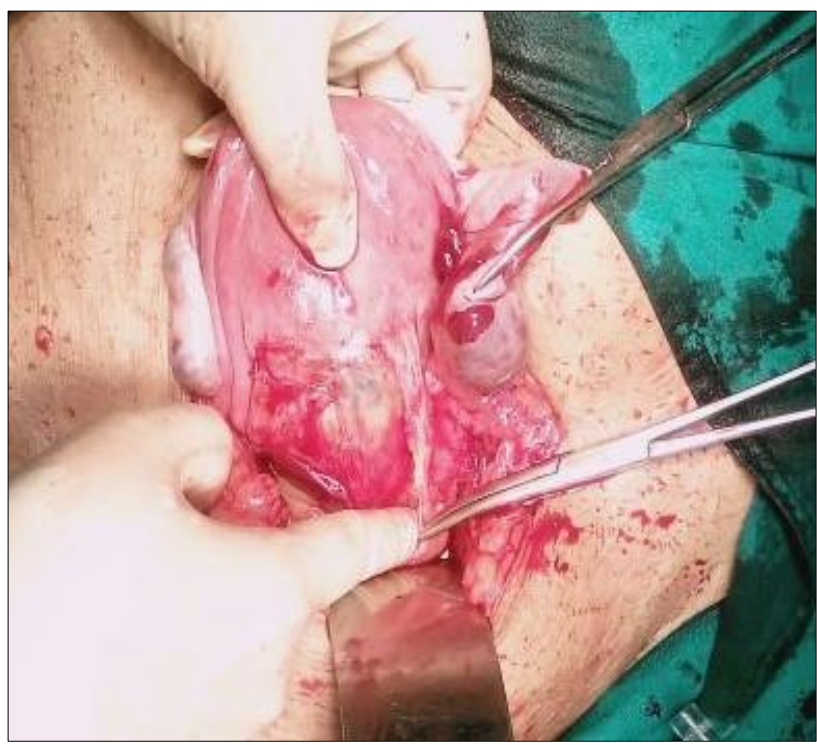

Figure 1: Gestational sac seen protruding through previous caesarean scar defect.

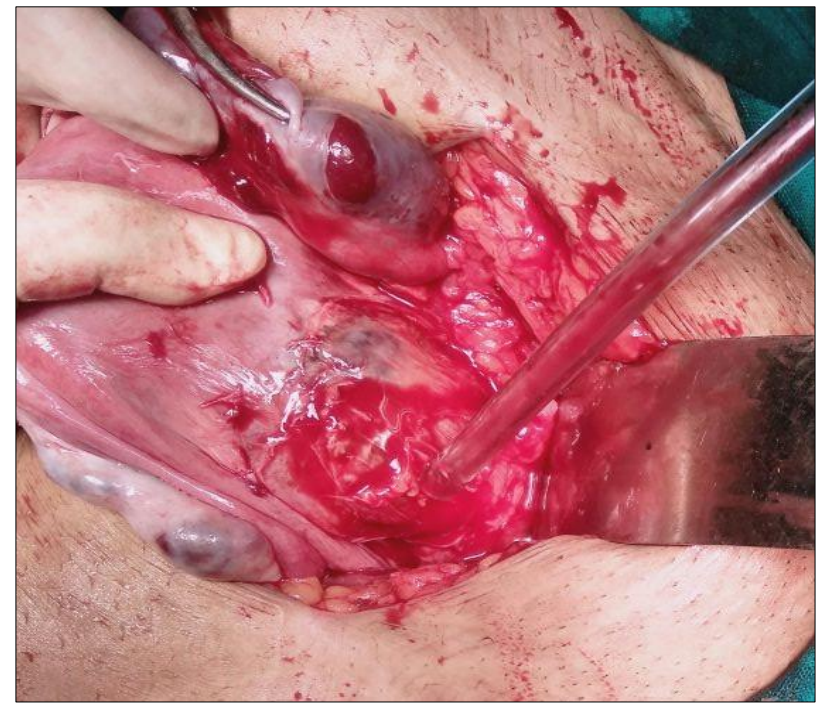

Figure 2: Ruptured left ovarian corpus luteal cyst which has been clamped to stop further bleeding.

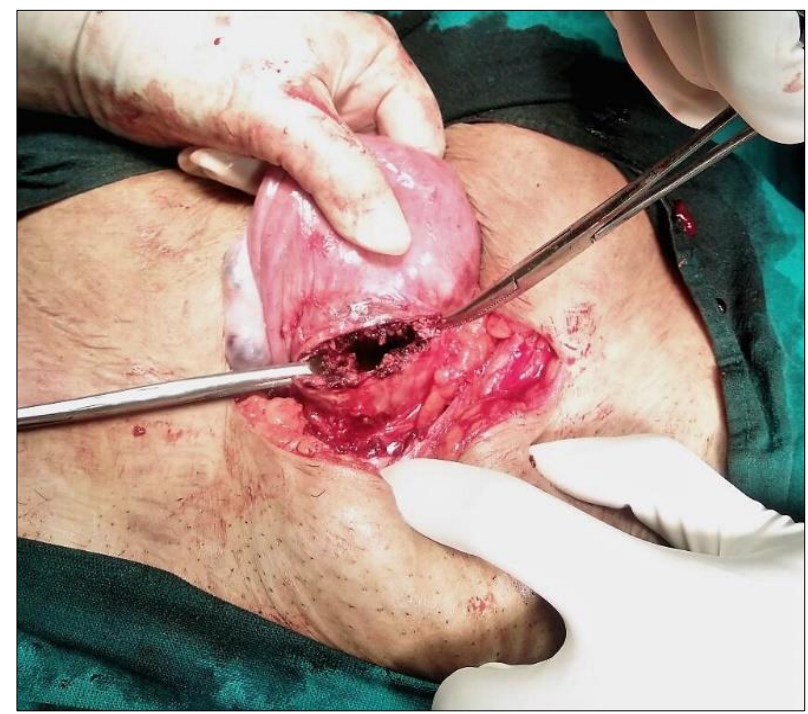

Figure 3: Uterus after evacuation of c scar pregnancy products through previous scar and uterine defect showing in figure has been repaired in two layers.

Possibility of ruptured ovarian ectopic and scar ectopic pregnancy was kept and exploratory laparotomy performed. Intraoperatively, we found approx. one liter of haemoperitoneum with ruptured left ovarian haemorrhagic cyst with ballooning of lower uterine segment with areas of dusky blue discoloration on uterine scar and bulging of gestational sac through uterine scar but uterus was not ruptured, serosal membrane was still intact (Figure 1). ruptured left ovarian cyst leading to intra-pertinoneal haemorrhage (Figure 2). Ruptured left ovarian cyst excision done followed by Incision was given over bulge and products of conception were gently removed. It was communicating with uterine cavity, edges of scar tissue were excised and freshened, gentle uterine curettage was done (Figure 3). Patient received three units of packed cell volume intraoperatively. and 
day one postop lab reports including coagulation profile was done and came with in normal limits. Her postoperative period was uneventful and was discharged on the fifth postoperative day. Histopathology report s/o trophoblastic tissue with smooth muscle fibre confirms caesarean scar pregnant and cyst wall s/o corpus luteal cyst (Figure 4 and 5).

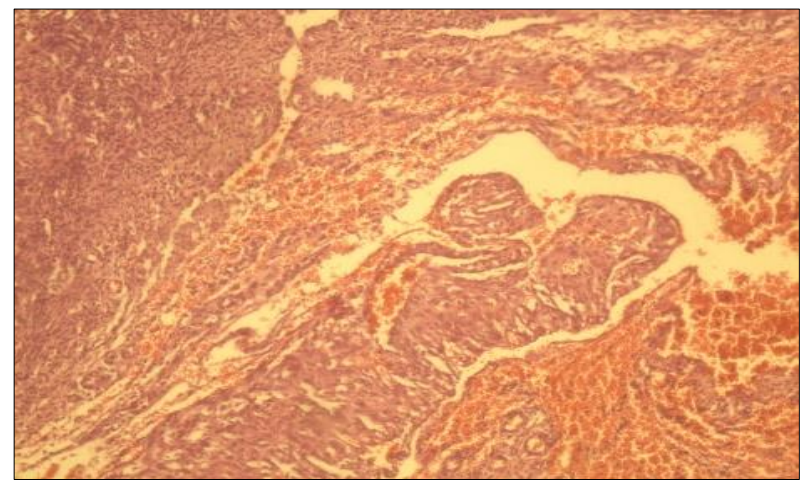

Figure 4: Histopathology report s/o hemorrhagic corpus luteum.

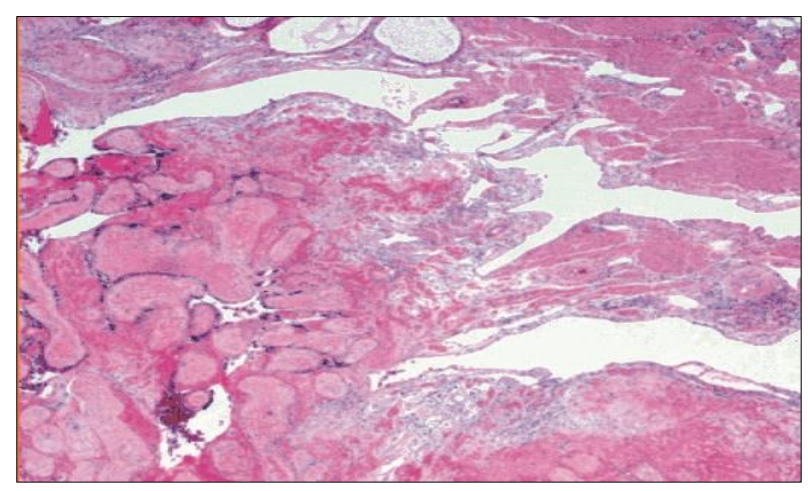

Figure 5: Chorionic villi with smooth muscle s/o caesarean scar ectopic

\section{DISCUSSION}

A caesarean scar ectopic pregnancy is considered to be the rarest form of ectopic pregnancy and constitutes a life-threatening condition. Caesarean section scar pregnancies have become more common because of the increasing rate of caesarean deliveries. The exact cause of implantation of the gestation into the scar of a previous caesarean section is not well understood.

The most probable mechanism explaining scar implantation is invasion by the implanting blastocyst through a microscopic tract that develops from the trauma of an earlier CS. ${ }^{6}$

Most women have a normal pregnancy following a CSP. The risk of recurrence has been reported as $3.2-5.0 \%$ in women with one previous CSP treated by dilatation and curettage with or without uterine artery embolisation. ${ }^{6,7}$
Women with CSP may present with slight vaginal bleeding and/or abdominal discomfort. ${ }^{8}$ Rarely, women may present with acute pain and profuse vaginal bleeding. It is not uncommon to diagnose CSP during or after attempted surgical evacuation for missed miscarriage haemodynamic instability and collapse in a suspected CSP.

Diagnosis and management of CSP needs considerable expertise and multidisciplinary approach to prevent complications.

Transvaginal three-dimensional (3D) ultrasound with power doppler may yield superior images including 3D images of the ectopic mass. It also identifies peritrophoblastic vascular flow in the tissue surrounding the sac and measurement of the myometrial thickness is relatively easier. ${ }^{9,10}$

\section{Ultrasound criteria for diagnosis of caesarean scar pregnancy $(\mathrm{CSP})^{11}$}

- Empty uterine cavity and closed and empty cervical canal

- Placenta and/or a gestational sac embedded in the scar of a previous caesarean section

- A triangular/round or oval-shaped gestational sac that fills the niche of the scar

- A thin or absent myometrial layer between the gestational sac and the bladder

- Yolk sac, embryo and cardiac activity may or may not be present

- Evidence of functional trophoblastic/placental circulation on color flow doppler examination, characterized by high velocity and low impedance blood flow

- Negative 'sliding organs' sign.

MRI is useful for making a reliable diagnosis in cases of uncertain clinical and ultrasound features. ${ }^{12}$

It can have life threatening complication affecting maternal morbidity and future fertility. The immediate complications of caesarean scar pregnancy are uterine rupture, severe bleeding, need for hysterectomy, and maternal morbidity. Our patient underwent emergency laparotomy and evacuation of product of conception from hysterotomy scar and repair of uterus with traditional methods. She left the hospital with an uneventful postoperative period.

\section{Management options for caesarean scar pregnancy (CSP)}

- Expectant management - use very rarely in selected cases

- Medical management - systemic methotrexate 
- Local injection and embolization - local injection of methotrexate with sac aspiration, local injection of other embryocides, uterine artery chemoembolisation

- Surgical management - dilatation and surgical evacuation, hysteroscopic resection, vaginal excision and resuturing, laparoscopic excision and resuturing, open excision and resuturing, combined laparoscopic and hysteroscopic procedure, combined laparoscopic and vaginal surgery, hysterectomy

- Combined or sequential management - uterine artery embolisation/ chemoembolisation followed by dilatation and evacuation/surgical resection in 24-48 hours, Methotrexate followed by surgical evacuation or resection after an interval.

\section{Factors influencing management choices}

- Patient factors: symptoms, patient fertility wishes, acceptability of prolonged follow up, associated lesions, surgical risk factors, response to initial treatment

- Caesarean scar pregnancy (CSP): gestational age, human chorionic gonadotropin (hCG) levels, size of CSP mass, type of CSP, myometrial thickness, viability

- Facilities: Interventional radiology, surgical expertise/facilities, monitoring facilities.

The time required for hCG levels to decline to nonpregnant levels and for the CSP mass to resolve completely varies and depends on factors such as the gestation time at diagnosis, hCG levels, size of the CSP and the method of treatment. Conservative medical management is associated with a longer time compared with surgical management. These women should be monitored until complete resolution of the CSP mass. Following the initial dose of methotrexate, hCG levels may go up and the size of the mass may increase due to trophoblastic necrosis and haemorrhage around the sac. $^{13,14}$

The corpus luteum is a functional cyst which develops in the luteal phase of the ovarian cycle and regresses into the corpus albicans when pregnancy does not occur. Given its thin-walled vascular structure it is easily prone to haemorrhage. Rarely the cyst-walled structure ruptures causing haemorrhage to spread into the peritoneal cavity resulting in a haemoperitoneum. In unclear cases, some reports recommend a "wait and see" approach constituting serial b-HCG levels and repeat ultrasound imaging. In our case the patient had a positive pregnancy test with a litre of blood in her abdomen. Hence surgical intervention was necessary as she was already on the path to becoming haemodynamically unstable. This case highlights the importance of considering haemoperitoneum secondary to corpus luteal cyst rupture, in a fit and healthy woman, as a differential diagnosis in the acute abdomen.

\section{CONCLUSION}

The distinction between normal early pregnancy and early pregnancy complications can be challenging. haemoperitoneum from a ruptured corpus luteal cyst supporting pregnancy can be a life-threatening surgical condition. This case highlights the importance of considering a ruptured corpus luteal cyst in the differentials of an acute abdomen. Diagnosis and management of CSP needs considerable expertise and a multidisciplinary approach to prevent complications. Increasing CS rates imply that clinicians will encounter CSP from time to time. A primary preventive strategy is to focus on reducing the number of primary CS performed without medical indications. The risk of longterm complications such as CSP and placenta accreta should be specifically emphasised when counselling women requesting CS for nonmedical reasons. Prompt and accurate diagnosis of CSP and individualised treatment and follow up are required to reduce overall morbidity.

\section{Funding: No funding sources \\ Conflict of interest: None declared \\ Ethical approval: Not required}

\section{REFERENCES}

1. Seow KM, Huang LW, Lin YH, Lin MY, Tsai YL, Hwang JL. Caesarean scar pregnancy: issues in management. Ultrasound Obstet Gynecol. 2004;23:247-53.

2. Jurkovic D, Hillaby K, Woelfer B, Lawrence A, Salim R, Elson CJ. First trimester diagnosis and management of pregnancies implanted into the lower uterine segment Caesarean section scar. Ultrasound Obstet Gynecol. 2003;21:220-7.

3. Rotas MA, Haberman S, Levgur M. Caesarean scar ectopic pregnancies: aetiology, diagnosis, and management. Obstet Gynecol. 2006;107:1373-81.

4. Fylstra DL. Ectopic pregnancy within a caesarean scar: a review. Obstet Gynecol Surv. 2002;57:53743.

5. Ash A, Smith A. Maxwell. Caesarean scar pregnancy. BJOG. 2007;114:253-63.

6. Qian ZD, Guo QY, Huang LL. Identifying risk factors for recurrent caesarean scar pregnancy: a case-control study. Fertil Steril. 2014;102:129-34.

7. Ben Nagi J, Helmy S, Ofili-Yebovi D, Yazbek J, Sawyer E, Jurkovic D. Reproductive outcomes of women with a previous history of Caesarean scar ectopic pregnancies. Hum Reprod. 2007;22:2012-5.

8. Zhang Y, Gu Y, Wang JM, Li Y. Analysis of cases with caesarean scar pregnancy. J Obstet Gynaecol Res. 2013;39:195-202.

9. Wang CJ, Yuen LT, Yen CF, Lee CL, Soong YK. Three-dimensional power Doppler ultrasound diagnosis and laparoscopic management of a pregnancy in a previous caesarean scar. J Laparoendosc Adv Surg Tech. 2004;14:399-402. 
10. Shish JC. Caesarean scar pregnancy: diagnosis with three-dimensional (3D) ultrasound with 3D power Doppler. Ultrasound Obstet Gynecol. 2004;23:306-7.

11. Timor-Tritsch IE, Monteagudo A, Santos R, Tsymbal T, Pineda G, Arslan AA. The diagnosis, treatment, and follow-up of caesarean scar pregnancy. Am J Obstet Gynecol. 2012;207:44.e113.

12. Koroglu M, Kayhan A, Soylu FN, Erol B, SchmidTannwald C, Gurses C, et al. MR imaging of ectopic pregnancy with an emphasis on unusual implantation sites. Jpn J Radiol. 2013;31:75-80.

13. Timor-Tritsch IE, Monteagudo A. Unforeseen consequences of the increasing rate of caesarean deliveries: early placenta accreta and caesarean scar pregnancy: a review. Am J Obstet Gynecol. 2012;207:14-29.

14. Deb S, Clewes J, Hewer C, Raine-Fenning N. The management of caesarean scar ectopic pregnancy following treatment with methotrexate - a clinical challenge. Ultrasound Obstet Gynecol. 2007;30:88992.

Cite this article as: Yadav S, Mukherjee S. Cesarean scar ectopic with ruptured corpus luteal cyst: a rare case report. Int J Reprod Contracept Obstet Gynecol 2020;9:853-7. 